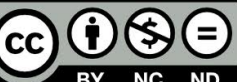

\title{
POLÍTICAS PÚBLICAS DE INCLUSÃO EDUCACIONAL - IGUALDADE E DIFERENÇA: VALORES INDISSOCIÁVEIS?
}

\author{
PUBLIC POLICIES OF EDUCATIONAL INCLUSION - EQUALITY AND DIFFERENCE: \\ INSEPARABLE VALUES? \\ POLÍTICAS PÚBLICAS DE INCLUSIÓN EDUCATIVA - IGUALDAD Y DIFERENCIA: \\ ¿VALORES INSEPARABLES?
}

Fátima Garcia Chaves Universidade de Uberaba - UNIUBE

E-mail: fgc@uberabadigital.com.br

\section{RESUMO}

Políticas públicas no âmbito educacional têm sido implementadas para que a escola se torne inclusiva. Esforços têm sido investidos para que os discentes tenham suas diferenças consideradas nos processos de ensino-aprendizagem. Este artigo objetiva conhecer as políticas públicas de inclusão educacional e refletir sobre as questões da igualdade e da diferença, pois essas são relevantes para a (re) constituição de um trabalho comprometido com a educação inclusiva no âmbito escolar. Diante da diversidade, a escola precisa desenvolver um trabalho educativo com ações de cunho realmente inclusivo. O respeito à diferença implica dar voz e vez a cada um em sua singularidade, para estabelecer relações de igualdade. A escola tem um papel importante para quebrar as questões do preconceito e possibilitar melhores relações sociais.

PALAVRAS-CHAVE: Políticas públicas. Inclusão. Diversidade.

\section{ABSTRACT}

Public policies in the educational field have been implemented so that the school becomes inclusive. Efforts have been invested so that students have their differences considered in the teaching-learning processes. This article aims to know the public policies of educational inclusion and to reflect on the issues of equality and difference, since these are relevant to the (re) constitution of work committed to inclusive education in the school context. In the face of diversity, the school must develop an educational work with truly inclusive actions. Respect for difference implies giving voice and time to each one in his singularity, to establish relations of equality. The school has an important role to break the issues of prejudice and enable better social relations.

KEYWORDS: Public policies. Inclusion. Diversity.

\section{RESUMEN}

Las políticas públicas en el ámbito educativo han sido implementadas para que la escuela se haga inclusiva. Esfuerzos han sido invertidos para que los alumnos tengan sus diferencias consideradas en los procesos de enseñanzaaprendizaje. Este artículo tiene como objetivo conocer las politicas públicas de inclusión educativa y reflexionar sobre las cuestiones de igualdad y de diferencia, pues éstas son relevantes para la (re) constitución de un trabajo comprometido con la educación inclusiva en el ámbito escolar. Ante la diversidad, la escuela necesita desarrollar un trabajo educativo con acciones de cuño realmente inclusivo. El respeto a la diferencia implica dar voz y vez a cada uno en su singularidad, para establecer relaciones de igualdad. La escuela tiene un papel importante para romper las cuestiones del prejuicio y posibilitar mejores relaciones sociales. 


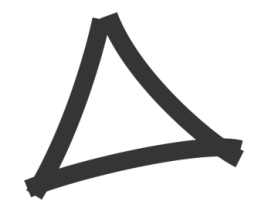

Revista Triângulo

www.seer.uftm.edu.br/revistaeletronica

\section{INTRODUÇÃO}

... Mire, veja; o mais importante e bonito do mundo é isto; que as pessoas não estão sempre iguais, ainda não foram terminadas, mas que elas vão sempre mudando. Afinam ou desafinam.

João Guimarães Rosa, Grande Sertão: Veredas.

Art. $3^{\circ}$ - I - construir uma sociedade livre, justa e solidária; II - garantir o desenvolvimento nacional; III - erradicar a pobreza e a marginalização e reduzir as desigualdades sociais e regionais; IV - promover o bem de todos, sem preconceitos de origem, raça, sexo, cor, idade e quaisquer outras formas de discriminação. (BRASIL, 1988)

Ainda que a Constituição da República Federativa do Brasil de 1988, nos aponte para uma visão de sociedade justa, igualitária, sem qualquer tipo de discriminação e preconceito há a necessidade de se falar em inclusão. Isto porque muitos têm sido excluídos, marginalizados nas esferas social e educacional.

Nesta perspectiva, é relevante pensar sobre o que é estar ou ser incluído, ou refletir sobre quem são os excluídos e como os seres humanos são ou se tornam excluídos.

Para os autores (COPPETE; FLEURI; STOLTZ, 2012, p. 233) "a diversidade vem se constituindo como um dos principais fatores de visibilidade nos contextos educacionais. Sua presença tem sido notória no palco dos debates relacionados à educação no Brasil, principalmente nos últimos dez anos".

Constata-se a preocupação com a diversidade cultural, a partir do final dos anos de 1990 e, essa preocupação se evidencia em relação às políticas educacionais, como exemplo a

corporação da pluralidade cultural como tema transversal nos Parâmetros Curriculares Nacionais; a definição de um capítulo específico para abordar a educação especial; assim como os artigos voltados à educação indígena na Lei de Diretrizes e Bases da Educação Nacional LDB - N. 9.394/96; o Plano Nacional de Educação de 2001, com capítulos destinados à educação especial e educação indígena; a definição do dia 20 de novembro como dia da Consciência Negra; além das leis 10.639/03, que torna obrigatório o ensino da história e da cultura afro-brasileira e africana em todas as escolas do país; e a Lei n. 11.645/08, que insere a questão indígena nos currículos escolares (COPPETE; FLEURI; STOLTZ, 2012, p. 235)

Segundo a autora Vianna (2012, p.3), é no governo Lula 


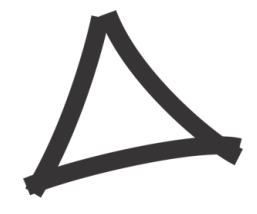

Revista Triângulo

www.seer.uftm.edu.br/revistaeletronica

que a diversidade passa a ser reconhecida a partir da negociação e da representatividade no governo de diversos atores políticos, como integrantes não só de programas e projetos, mas da própria organização administrativa, ocasionando uma modificação no modelo institucional de algumas secretarias, inexistente nos governos anteriores.

São criadas várias secretarias especiais, entre elas: a Secretaria Especial de Direitos Humanos (SEDH), a Secretaria Especial de Política para Mulheres (SPM), a Secretaria Especial da Promoção da Igualdade Racial (SEPPIR) e a Secretaria Nacional da Juventude (SNJ). [...]

Sob as injunções desses processos se materializa a ênfase na inclusão social, mas também se organizam novas institucionalidades. No âmbito específico do Ministério da Educação institui-se a Secretaria de Inclusão Educacional (SECRIE) e a Secretaria Extraordinária de Erradicação do Analfabetismo (SEEA). E com a fusão destas secretarias, em abril de 2004, origina-se a Secretaria de Educação Continuada, Alfabetização e Diversidade (SECAD). Inicia-se então a tentativa de articular as ações de inclusão social com a valorização da diversidade e com o destaque às demandas até então invisibilizadas e não atendidas efetivamente pelos sistemas públicos de educação.

A partir da criação da SECAD, canalizaram-se para a agenda governamental do MEC temas e sujeitos que dela estavam excluídos. Com a presença desses setores nos espaços da administração pública assistimos à conversão de antigas denúncias em propostas de políticas públicas federais.

A Fundação Instituto de Pesquisas Econômicas - FIPE vinculada à Faculdade de Economia, Administração e Contabilidade (FEA) da Universidade de São Paulo (USP), firmou convênio ( ${ }^{\circ}$ 35/2008, celebrado em junho de 2008) com o Instituto Nacional de Estudos e Pesquisas Educacionais Anísio Teixeira - INEP, para realizar o projeto de Estudo sobre Ações Discriminatórias no Âmbito Escolar. Essa pesquisa divulgada em 2009 pela (FIPE) foi realizada em 501 escolas públicas brasileiras e revelou dados alarmantes sobre o preconceito no ambiente escolar do país. Os tipos de preconceito que apresentaram maior abrangência são aqueles relacionados a pessoas com deficiência (96,5\%), seguido por diferenças étnico-raciais $(94,2 \%)$ e aqueles relativos a diferenças de gênero $(93,5 \%)$.

Nesta perspectiva, este artigo objetiva conhecer as políticas públicas de inclusão educacional e refletir sobre as questões da igualdade e da diferença, pois essas são relevantes para a (re) constituição de um trabalho comprometido com a educação inclusiva no âmbito escolar, uma vez que segundo a pesquisa da FIPE os resultados apresentados são alarmantes, assustadores. A pesquisa revela que as pessoas não admitem ter preconceitos em relação a outros grupos sociais aos 


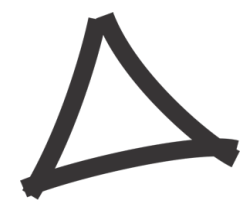

quais não pertencem, mas revelam predisposição em manter menor proximidade com alguns grupos, como homossexuais, deficientes etc. (BRASIL, 2009).

É importante destacar que os sistemas de ensino universalizam o acesso, mas continuam excluindo pessoas e grupos considerados fora dos padrões homogeneizadores da instituição escolar. Sabe-se que historicamente, a escola se caracterizou por uma educação que limita a escolarização como privilégio de um grupo, uma exclusão legitimada. Ela tem acolhido grupos sociais que antes não recebia e, consequentemente, tem encontrado inúmeros desafios demandados por estes, até então invisibilizados. Logo, estes desafios ocasionam perversas e diferentes formas de exclusão.

Esta invisibilidade nos remete a Foucault que ao longo de toda a sua vida investigou as margens, os invisíveis, os interditos, aqueles e aquilo que se objetivava manter distância. Ele causou um verdadeiro desconforto na linearidade das academias francesas. A loucura, os internatos, a prisão, o hospital psiquiátrico, a sexualidade, temas profundamente subversivos na academia e no senso comum saem dos escombros, perdem sua invisibilidade (PICCOLO, 2012).

"Enquanto todos olhavam para o centro, Foucault fazia questão de direcionar seu olhar para as margens, para os diferentes, para os desviados" (PICCOLO, 2012, p. 80).

Hospitais, escolas, fábricas, prisões, asilos, internatos, hospícios, todas essas instituições, profundamente marcadas pela disciplina, passam a ser coextensivas a modernidade e, mais que isso, começa a desempenhar um papel fundamental na sociedade capitalista como verdadeira peneira social que separa os incluídos e excluídos, os de dentro e de fora, os corpos úteis e descartáveis [...] (PICCOLO, 2012).

De fato, desde que a escola foi criada não tem considerado as diferenças entre os discentes, organizando-se com base na indiferença a essas diferenças, como salienta Rodrigues (2003, p. 9192): Assim, a escola "foi (é?) Uma fonte de exclusão para muitos alunos que, quase sempre, viram confundidos com "falta de motivação", "indisciplina" ou "falta de inteligência" a incompatibilidade entre seus valores, ritmos e interesses com os que eram veiculados na escola".

Ao falarmos sobre a inclusão no espaço da escola, devemos também questionar, como faz o pesquisador Rodrigues (2003, p. 1): "pode a escola ser inclusiva numa sociedade que não o é?" $\mathrm{Na}$ 


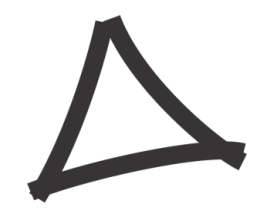

Revista Triângulo

www.seer.uftm.edu.br/revistaeletronica

modalidade Educação Especial, o que é o especial? É uma forma especial de entender uma educação para determinadas pessoas? "Em si" é uma caracterização excludente, dos sujeitos a partir da deficiência que possuem?

Nesta perspectiva, a Educação Inclusiva assume um lugar central no debate acerca do papel da escola: é preciso garantir as condições de acesso à escola, mas isto basta? Isto não basta! É preciso garantir a aprendizagem para TODOS os estudantes. Mas isto também não basta! Segundo Vianna e Silva (2014, p. 8), é necessário discutir como se situa a escola na sociedade e como esta sociedade produz seus excluídos, bem como reage a eles em várias instâncias, uma delas sendo a formação de professores que, na escola, dizem-se incapazes de lidar com alunos diferentes daqueles com os quais estão habituados.

Políticas públicas no âmbito educacional têm sido pensadas e implementadas para que a escola se torne inclusiva. Neste sentido, esforços têm sido investidos para que os discentes tenham suas diferenças consideradas nos processos de ensino e aprendizagem.

A Lei Federal de Diretrizes e Bases da Educação 9.394/1996 e a Resolução CNE/CEB 02/2001, que institui Diretrizes Nacionais para a Educação Especial na Educação Básica, falam sobre o trabalho com um currículo diferenciado e flexibilizado aos alunos que fazem parte do público alvo da Educação Especial.

O Ministério da Educação por meio da Secretaria de Educação Especial apresentou, em 2008, a Política Nacional de Educação Especial na Perspectiva da Educação Inclusiva (BRASIL, 2008) que institui uma mudança estrutural na instituição escolar, implementando políticas públicas de inclusão educacional visando a uma educação de qualidade para todos os alunos. Entre as orientações para esta mudança estão:

- transversalidade da educação especial desde a Educação Infantil até a educação superior;

- atendimento educacional especializado;

- continuidade da escolarização nos níveis mais elevados do ensino;

- formação de professores para o atendimento educacional especializado e demais profissionais da educação para a inclusão escolar; 


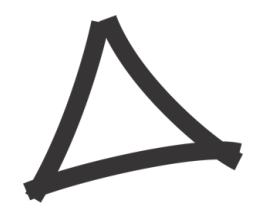

Revista Triângulo

www.seer.uftm.edu.br/revistaeletronica

- participação da família e da comunidade;

- acessibilidade urbanística, arquitetônica, nos mobiliários e equipamentos, nos transportes, na comunicação e informação; e

- articulação intersetorial na implementação das políticas públicas.

Segundo este documento,

O movimento mundial pela educação inclusiva é uma ação política, cultural, social e pedagógica, desencadeada em defesa do direito de todos os alunos de estarem juntos, aprendendo e participando, sem nenhum tipo de discriminação. A educação inclusiva constitui um paradigma educacional fundamentado na concepção de direitos humanos, que conjuga igualdade e diferença como valores indissociáveis, e que avança em relação à ideia de equidade formal ao contextualizar as circunstâncias históricas da produção da exclusão dentro e fora da escola (2008, p. 1).

Enquanto a diferença é colocada em evidência nas políticas governamentais, provocando mudanças, ainda há resistências no interior das instituições escolares. Daí a relevância de tais políticas e, uma das ações que tem possibilitado mudanças importantes na (re) organização escolar é a oferta do Atendimento Educacional Especializado (AEE). Este está fundamentado na Constituição Federal de 1988 e nos documentos legais a seguir:

- Resolução CNE/CEB No 04/2009 e Parecer CNE/CEB Nº 13/2009, que estabelecem as Diretrizes Operacionais para o Atendimento Educacional Especializado na Educação Básica.

- Decreto Federal No 7611/2011que dispõe sobre a oferta de atendimento educacional especializado, compreendido como o conjunto de atividades, recursos de acessibilidade e pedagógicos organizados institucional e continuamente (Art. $2^{\circ}, \S 1^{\circ}$ ), como também sobre a distribuição do FUNDEB no que se refere à dupla matrícula do aluno, ou seja, no ensino regular e no atendimento educacional especializado (AEE).

Neste sentido, é importante destacar que nesta organização e/ou reorganização da escola, no sentido de torná-la inclusiva, quem são estes alunos que fazem parte da Educação Especial e que possuem este amparo legal. Segundo o documento Política Nacional de Educação Especial na Perspectiva da Educação Inclusiva (2008) são os discentes com: deficiência; transtornos globais de desenvolvimento e os de altas habilidades/superdotação. 


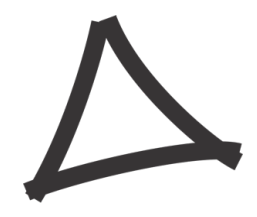

Revista Triângulo

www.seer.uftm.edu.br/revistaeletronica

Percebe-se que estes grupos, de certa forma têm seu amparo legal e os demais grupos sociais que também apresentam suas particularidades/ necessidades, continuarão marginalizados, excluídos? O que se tem feito para eles na perspectiva de inclusão educacional? E estes com amparo legal, não são mais excluídos? Tais políticas por si só já bastam?

\subsection{As diferenças.... Um direito? (In) visibilidade?}

Sabemos que a "diferença" foi evidenciada graças aos resultados de lutas históricas dos movimentos sociais por direitos de cidadania e de igualdade para todos.

Neste sentido, na obra Ciladas da diferença, Antônio Flávio Pierucci destaca em seu primeiro capítulo a causa dos perigos que a bandeira da diferença apresentada pela esquerda e os novos movimentos sociais (dos negros, dos índios, das mulheres, das minorias étnicas) teve sua origem na direita. Ele destaca (1999, p. 19)

a certeza de que os seres humanos não são iguais porque não nascem iguais $\mathrm{e}$, portanto não podem ser tratados como iguais quem primeiro a professou e apregoou nos tempos modernos foi a direita. Para ser historiograficamente mais exato, foi a ultradireita do final do século XVIII e primeiras décadas do XIX, aliás, a primeira direita a surgir na história, em reação à Revolução Francesa, ao ideal republicano de igualdade e fraternidade e a tudo de universalismo e igualitarismo havia no movimento das ideias filosóficas do século XVIII.

Diferentes discursos políticos foram/são construídos em torno a "tolerar" ou "respeitar". É nesta perspectiva, que indago: como a igualdade de direitos e o direito à diferença são vivenciados na escola?

A diferença é parte ativa da formação das nossas identidades, do modo como nos tornamos aquilo que somos. Para Silva (2007) a identidade e a diferença são o resultado de um processo de produção simbólica e discursiva. A identidade, tal como a diferença, é uma relação social. Isso significa que sua definição - discursiva e linguística - está sujeita a vetores de força, a relações de poder. Elas não são simplesmente definidas; elas são impostas. Elas não convivem harmoniosamente, lado a lado, em um campo sem hierarquias; elas são disputadas. 


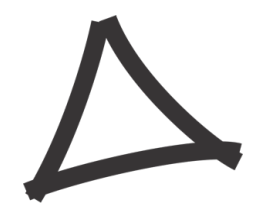

Pode-se dizer então que onde existe identidade e diferença - há a presença do poder. Há, entretanto, outras tantas marcas da presença do poder: incluir/excluir ("estes pertencem, aqueles não"); demarcar fronteiras ("nós" e "eles"); classificar ("bons e maus"; "puros e impuros"; "desenvolvidos e primitivos"; "racionais e irracionais"); normalizar ("nós somos normais; eles são anormais") (SILVA, 2007).

Neste contexto, é relevante pensar que "a definição de normal depende da definição de anormal e que este par normal/anormal acompanha a humanidade em diversos lugares e épocas" (VIANNA; SILVA, 2014, p. 9). Segundo os autores falar do que é normal equivale a demarcar fronteiras, estabelecendo o que pode ficar dentro e o que pode ficar fora e é aí que se instaura a inclusão e a exclusão.

Neste sentido, nota-se que na escola dispositivos de normalização são acionados cotidianamente. Como e por que isso acontece? Os professores percebem isto? É importante que os professores entendam como estas coisas acontecem, porque a escola já se encontra organizada de modo não inclusivo promovendo várias diferenciações: entre disciplinas (algumas mais valorizadas, outras menos), entre professores (alguns considerados melhores que os outros) e entre alunos também. O autor Correa (2004, p. 1) corrobora quando destaca

\begin{abstract}
[...] aprendemos, pelo hábito, os modos muito particulares que a escola tem de nos oferecer um conhecimento do mundo implicado no isolamento deste mundo a conhecer nas salas de aula. Nestas celas aprendemos os lugares e o fluxo vertical do conhecimento marcado por hierarquias: hierarquia de funções (quem sabe ensina a quem não sabe), hierarquia dos saberes (os saberes da escola são qualificados por agentes do governo), hierarquia das posições (o lugar de quem sabe e o lugar de quem não sabe).
\end{abstract}

Para o autor Tomaz Tadeu Silva (2007), a afirmação da identidade e a marcação da diferença implicam, sempre, as operações de incluir e de excluir. Como vimos, dizer "o que somos" significa também dizer "o que não somos". A identidade e a diferença se traduzem, assim, em declarações sobre quem pertence e sobre quem não pertence, sobre quem está incluído e quem está excluído.

Veiga Neto, no artigo "Incluir para excluir" discute algumas das dificuldades e ambiguidades que enfrentam as políticas que pretendem fazer a inclusão escolar dos anormais, justamente em decorrência, da própria construção moderna da normalidade. Ele destaca

\begin{tabular}{l|l|l|l|l|l|l|} 
(C) Rev. Triang. & Uberaba, MG & v.11 & n.1 & p. 212-224 & Jan./Abr. 2018 & ISSN 2175-1609
\end{tabular}




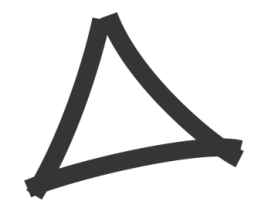

Revista Triângulo

www.seer.uftm.edu.br/revistaeletronica

De um lado, essas políticas têm esbarrado na resistência de muitos educadores conservadores. De outro lado, elas têm enfrentado dificuldades de ordem epistemológica ou mesmo prática, seja quando pretendem tratar de modo generalizante e indiferenciado as inúmeras identidades culturais que "povoam" aquilo que se costuma denominar de "todo social", seja quando não levam em consideração que tais identidades culturais têm suas raízes em camadas muito mais profundas do que fazem crer aqueles discursos progressistas mais simplificadores, que costumam ver o mundo sempre a partir da famosa dicotomia dominadores - dominados, exploradores - explorados. (2003, p. 109).

Segundo o autor Veiga-Neto (2003, p. 110)

Se parece mais difícil ensinar em classes inclusivas, classes nas quais os (chamados) normais estão misturados com os (chamados) anormais, não é tanto porque seus (assim chamados) níveis cognitivos são diferentes, mas, antes, porque a própria lógica de dividir os estudantes em classes por níveis cognitivos, por aptidões, por gêneros, por idades, por classes sociais foi um arranjo inventado para justamente, colocar em ação a norma, através de um crescente e persistente movimento de, separando o normal do anormal, marcar a distinção entre normalidade e anormalidade. [...] A própria organização do currículo e da didática, na escola moderna, foi pensada e colocada em funcionamento para, entre várias outras coisas, fixar quem somos nós e quem são os outros.

Para Veiga Neto, não bastam vontade política e competência técnica (para lidar com o anormal), para que se implemente com sucesso a inclusão. Se não forem levadas em conta a variada tipologia da anormalidade e a sua própria gênese, ou se não se conhecer, como disse Skliar (1999, p.26), "qual é a política de significados e as representações que se produzem e reproduzem nessa proposta".

Veiga-Neto salienta que "as políticas de inclusão têm de, necessária e antecipadamente, levar em conta tal multiplicidade. Colocar todos os anormais num mesmo plano significa não atentar para as peculiaridades culturais que se estabelecem em cada grupo" (2003, p. 117).

Quando se discute a inclusão, é comum ocorrerem nos âmbitos escolares a eliminação/diminuição de conteúdos básicos, como por exemplo, a proposta de currículos alternativos. Esta é uma prática de inclusão? Ao inserir este aluno na sala de aula e eliminar e/ou diminuir os conteúdos, que mudanças na perspectiva inclusiva estão sendo delineadas? 
Seria ideal, construir um currículo no qual a diferença seja considerada como ponto inicial para a elaboração de propostas pedagógicas que contemplem as reais necessidades dos alunos.

Nesta perspectiva, Rodrigues (2003, p. 92) colabora quando diz que, na inclusão, a diferenciação curricular que se procura é aquela na qual “[...] não se separam os alunos com base em determinadas categorias, mas em que se educam os alunos em conjunto, procurando aproveitar o potencial educativo das suas diferenças $[\ldots . .$. ”.

Assim, é imprescindível ressaltar que as diferenças são relevantes no sentido inverso daquele que usualmente a escola as toma, elas são importantes não para "separar" os alunos em categorias, e sim para promover a inclusão, elas são importantes para promover o convívio, a aprendizagem de uns com os outros e não para justificar a segregação.

\section{CONSIDERAÇÕES FINAIS}

Para Candau (2008, p. 1), “globalização, políticas neoliberais, segurança global, estas são realidades que estão acentuando a exclusão, em suas diferentes formas e manifestações. No entanto, não afetam igualmente a todos os grupos sociais e culturais, nem a todos os países e, dentro de cada país, às diferentes regiões e pessoas".

A autora explica este dualismo, para alguns a construção da democracia enfatiza as questões relativas à igualdade, eliminando ou relativizando as diferenças. Outros defendem um multiculturalismo radical, enfatizando a diferença e a igualdade ficando em segundo plano. $\mathrm{Na}$ opinião dela, "não é afirmar um polo e negar o outro, mas sim termos uma visão dialética da relação entre igualdade e diferença" (2008, p. 1). Hoje em dia não se pode falar em igualdade sem incluir a questão da diversidade, nem se pode abordar a questão da diferença dissociada da afirmação da igualdade. 


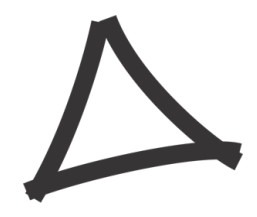

Assim, é necessário vivenciar a inclusão na educação como uma proposta da sociedade e da escola e não como algo imposto. Diante da diversidade, a escola precisa desenvolver um trabalho educativo com ações pensadas, refletidas, de cunho realmente inclusivo. O respeito à diferença implica dar voz e vez a cada um em sua singularidade, para estabelecer relações de igualdade. A escola tem um papel importante para quebrar as questões do preconceito e possibilitar melhores relações sociais.

É preciso de um intenso e sistematizado trabalho transformando a cultura do âmbito escolar, mudando os modos de ser e estar e, as práticas existentes nesses espaços. A escola na perspectiva inclusiva propõe uma ruptura não só com as práticas, mas principalmente com os valores da escola tradicional. Ela precisa romper com a ideia de uma proposta curricular única, de aluno padrão, de ensino apenas transmissivo e com o modelo de escola como estrutura de reprodução.

Segundo Vianna (2012) essa é uma tarefa difícil e requer luta em todas as esferas, dentro e fora da escola: na conscientização e formação do corpo docente; na discussão de propostas e atividades realizadas na escola; na análise crítica dos livros didáticos; na denúncia das revelações ditas científicas que perpetuam preconceitos e, sobretudo, nas inúmeras reivindicações por direitos à diferença. Assim, quem sabe, possamos mesmo contribuir para a construção de uma sociedade mais justa e menos desigual.

Para terminar, deixo aqui a expressividade do subcomandante Marcos (2001), palavras poéticas expressas no artigo da autora Vera Maria Candau "Multiculturalismo e direitos humanos" que mexeram profundamente comigo e acredito que com você também:

A Dignidade exige que sejamos nós mesmos.

Mas a Dignidade não é somente que sejamos nós mesmos.

Para que haja Dignidade é necessário o outro.

E o outro só é outro na relação conosco.

A Dignidade é então um olhar.

Um olhar a nós mesmos que também se dirige ao outro olhando-se e olhando-nos.

A Dignidade é então reconhecimento e respeito.

Reconhecimento do que somos e respeito a isto que somos, sim, mas também reconhecimento do que é o outro e respeito ao que ele é.

A Dignidade é ponte e olhar e reconhecimento e respeito.

Então a Dignidade é o amanhã. 


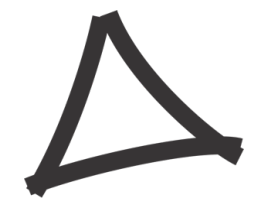

Revista Triângulo

www.seer.uftm.edu.br/revistaeletronica

Mas o amanhã não pode ser se não é para todos, para os que somos nós e para os que são outros.

A Dignidade é então uma casa que nos inclui e inclui o outro.

A Dignidade é então uma casa de um só andar, onde nós e o outro temos nosso próprio lugar, isto e não outra coisa é a vida, e a própria casa.

Então a Dignidade deveria ser o mundo, um mundo que tenha lugar para muitos mundos.

A Dignidade então ainda não é.

Então a Dignidade está por ser.

A Dignidade então é lutar para que a Dignidade seja finalmente o mundo.

Um mundo onde haja lugar para todos os mundos.

Então a Dignidade é e está por construir.

É um caminho a percorrer.

A Dignidade é o amanhã.

Esta construção é árdua, mas não impossível. Erguemos as mangas e iniciemos...

Um dia alguns frutos serão colhidos neste caminho, por nós ou por outros....

Não importa! Contribuiremos mesmo assim..

\section{REFERÊNCIAS}

BRASIL. Ministério da Educação. Lei de Diretrizes e Bases da Educação Nacional. LDB 9.394, de 20 de dezembro de 1996.

BRASIL. Ministério da Educação. Secretaria de Educação Especial. Diretrizes Nacionais para a Educação Especial na Educação Básica. Brasília: MEC/SEESP, 2001.

BRASIL. Ministério da Educação - Secretaria de Educação Especial. Política nacional de educação especial na perspectiva da educação inclusiva. Brasília: MEC/SEESP, 2008.

. Educação inclusiva: as boas e as más notícias. In: RODRIGUES, D. (Org.). Perspectivas sobre a inclusão: da educação à sociedade. Porto: Editora Porto, 2003.

BRASIL. Constituição da República Federativa do Brasil. 1988. http://www.planalto.gov.br/ccivil_03/constituicao/constituicaocompilado.htm

BRASIL. Fundação Instituto de Pesquisas Econômicas - FIPE. 2009. http://portal.mec.gov.br/dmdocuments/relatoriofinal.pdf
BRASIL.
Parecer
$\mathrm{CNE} / \mathrm{CEB}$
$\mathrm{N}^{\mathrm{o}}$
$13 / 2009$.

http://portal.mec.gov.br/dmdocuments/pceb013 09 homolog.pdf

BRASIL. Resolução CNE/CEB No 04/2009. http://portal.mec.gov.br/dmdocuments/rceb004_09.pdf

CANDAU, Vera Maria. Multiculturalismo e Direitos humanos. In: Multiculturalismo: diferenças culturais e práticas pedagógicas. Petrópolis: Ed. Vozes, p. 13-37, 2008. 


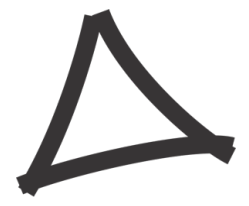

Revista Triângulo

www.seer.uftm.edu.br/revistaeletronica

COPPETE, M. C. FLEURI, R.M., STOLTZ, T. Educação para a Diversidade numa perspectiva intercultural. Revista Pedagógica Unochapecó, Ano-15, n. 28, vol. 01, jan./jun., 2012.

CORREA, Guilherme. Do livro de receitas: como produzir um homem. In: PASSETTI, Edson (org.). Kafka-Foucault: sem medos. Cotia: Ateliê Editorial, 2004.

MARCOS (sub-comandante) La Marcha del color de la tierra. (comunicados, cartas y mensajes del Ejército Zapatista de la Liberación Nacional del 2000 al 2 de abril del 2001) México, rizoma, 2001.

PICCOLO, G. M.; MENDES, E. G. Para além do natural: contribuições sociológicas a um pensar sobre a deficiência. In: MENDES, E. G.; ALMEIDA, M. A. (org.) A pesquisa sobre inclusão escolar em suas múltiplas dimensões: teoria, política e formação. Marília: ABPEE, 2012, p. 5390 .

PIERUCCI, Antônio Flávio. Ciladas da Diferença. São Paulo: Editora 34, 1999.

ROSA, João G. Grande Sertão: Veredas. Nova Fronteira, São Paulo, 2005.

SILVA, Tomaz Tadeus da. A produção social da identidade e da diferença. In: SILVA, T. T. et. al. (Org.). Identidade e diferença. Petrópolis: Vozes, 2007.

SKLIAR, C. A invenção e a exclusão da alteridade 'deficiente' a partir dos significados da normalidade. Educação \& Realidade, 24, jul./dez., 1999.

VEIGA-NETO, A. Incluir para Excluir. In: LARROSA, J; SKLIAR, C. (Orgs.) Habitantes de Babel: políticas e poéticas da diferença. Belo Horizonte: Autêntica, 2003.

VIANNA, C. R.; SILVA, R. A. F. da. Uma ilha de inclusão no mar de exclusão? Brasília: MEC/SEESP, 2014.

VIANNA, Cláudia. Gênero e Diversidade Sexual: desafios para a prática docente. Material de apoio do curso de Especialização em Ética, Valores e Cidadania na Escola, da UNIVESP, disciplina Convivência Democrática. UNIVESP, 2012. 